\title{
Use of Salvage Surgery or Stereotactic Radiosurgery for Multiply Recurrent Skull Base Chordomas: A Single- Institution Experience and Review of the Literature
}

\author{
Stella K. Yoo ${ }^{1}$ Ben A. Strickland ${ }^{2}$ Gabriel Zada ${ }^{2}$ Shelly X. Bian ${ }^{1}$ Adam Garsa ${ }^{1}$ Jason C. Ye \\ Cheng $\mathrm{Yu}^{2}$ Martin H. Weiss ${ }^{2}$ Bozena B. Wrobel ${ }^{3}$ Steven Giannotta ${ }^{2}$ Eric L. Chang ${ }^{1}$
}

\footnotetext{
${ }^{1}$ Department of Radiation Oncology, University of Southern California, Keck School of Medicine, Los Angeles, California, United States

${ }^{2}$ Department of Neurosurgery, University of Southern California, Keck School of Medicine, Los Angeles, California, United States

${ }^{3}$ Caruso Department of Otolaryngology Head and Neck Surgery, University of Southern California, Los Angeles, California, United States
}

\begin{abstract}
Address for correspondence Eric L. Chang, MD, FASTRO, Department of Radiation Oncology, Keck School of Medicine, University of Southern California, 1441 Eastlake Avenue, G-349, Los Angeles, CA 90033, United States (e-mail: eric.chang@med.usc.edu).
\end{abstract}

J Neurol Surg B 2021;82:161-174.

\begin{abstract}
Keywords

- chordoma

- skull base

- radiation therapy

- surgery

- recurrence

- Gamma Knife
\end{abstract}

\section{Introduction}

Chordomas are slowly growing tumors arising from the embryonic remnants of the notochord that are often locally destructive with high recurrence rates. ${ }^{1-3}$ Initial treatment is usually maximally safe surgical resection with consideration of some form of adjuvant radiotherapy. Most of the current literature supports fractionated radiation with charged particles or high-energy photons with rates of local control above $70 \%{ }^{4-8} \mathrm{~A}$ challenge in the management of skull base received

June 24, 2019

accepted after revision

November 9, 2019

published online

January 14, 2020 (c) 2020. Thieme. All rights reserved.

Georg Thieme Verlag KG,

Rüdigerstraße 14,

70469 Stuttgart, Germany
DOI https://doi.org/

10.1055/s-0039-3402019. ISSN 2193-6331. 
chordomas is in the recurrent setting as previous surgical resection may have altered the anatomy of the eloquent clival region or prior radiation may have approached dose tolerances for critical structures. ${ }^{9}$ Patients may have multiple repeated recurrences requiring various modalities of salvage treatment.

Salvage treatment options may be offered with curative intent. A recent publication by the Chordoma Global Consensus Group advocates a treatment strategy for isolated skullbase local relapses to undertake high-dose re-irradiation with or without maximal tumor resection as a first-line salvage recommendation. Other approaches including observation, debulking surgery, substandard radiation with lower doses, other local therapy (radiofrequency ablation or cryotherapy), systemic therapy, or best palliative care are reserved for those cases not amenable to salvage surgery or salvage high-dose radiation. $^{10}$

Few studies have reported outcomes with management of locally relapsed disease with either surgery or radiation. ${ }^{11-21}$ In the recurrent setting, stereotactic radiosurgery (SRS) is an attractive option for chordomas and other skull base tumors given its high conformality, high biologically equivalent dose, and few treatments. ${ }^{22-24}$ At our tertiary academic medical center, we have experience treating recurrent chordomas of the skull base with either salvage re-resection or radiotherapy using Gamma Knife radiosurgery (GKRS) or CyberKnife radiosurgery (CKRS). We report our experience including overall survival, progression-free survival (PFS) after initial therapy and each salvage treatment, and incidence of neurological toxicities. In addition, we provide a review of the literature pertaining to the management of recurrent skull base chordomas.

\section{Methods}

After receiving approval from the USC Institutional Review Board (IRB), we obtained a list of patients with pathologyverified chordoma from the neurosurgery and radiation oncology departments. Complementary data were obtained from the local cancer registry. All available hospital records were reviewed including patient demographics, tumor characteristics, operative reports, radiation treatment details, and follow-up visit documentation. Initial tumor location in the clivus (upper, middle, and lower) was defined by the Sekhar classification. ${ }^{25}$ Tumor size was measured on pretreatment imaging when available with the volume calculated as an ellipsoid of revolution with the equation volume equals $\mathrm{XYZ}$ dimensions multiplied by (pi/6).

All patients were diagnosed via pathologic confirmation with a biopsy or initial resection. Gross total resection (GTR), subtotal resection (STR), and tumor involvement of adjacent critical structures were determined based on operative report documentation or perioperative imaging. Patients were coded as receiving adjuvant radiation if this treatment was administered less than 6 months after resection. Otherwise, interventions occurring after 6 months were indicated as salvage intent unless documented otherwise.

All patients were contacted via phone for an IRB-approved standard interview questionnaire with verbal informed consent regarding current symptomology to assess their func- tional outcomes. Public registries provided date of death when available.

A Swimmer's Plot was generated to visually represent each patient case's treatment history. Kaplan-Meier curves were generated for overall survival and PFS for the total population from date of diagnosis as well as from date of initial therapies. For subsequent therapies, the PFS was the main outcome examined. Univariate analyses were performed using log-rank statistics and multivariate analyses were performed using the Cox proportional hazards model, both considering $p<0.05$ as statistically significant. All plots and statistical analyses were generated using JMP, Version 14. SAS Institute Inc., Cary, NC, 1989-2007.

\section{Literature Review}

A literature review was conducted using the PubMed database using the Boolean search terms ("skull base chordoma" OR "clival chordoma" OR "intracranial chordoma") AND ("relapse" OR "recurrent" OR "salvage") with the filters of English language and human subjects.

\section{Results}

Initial Treatment for De Novo Skull Base Chordomas

A total of 28 patients with pathologically confirmed chordoma of the skull base were treated at the Keck Hospital of the University of Southern California from 1996 to 2018. Eighteen of these patients with initial treatment performed at our institution and who had recurrent/progressive disease were included for retrospective review (-Fig. 1). The median age was 41 years with a range of 16 to 64 . The median follow-up was 98.6 months with a range of 16 to 215 months. Patient demographics, initial tumor characteristics, and treatment details are summarized in - Table $\mathbf{1}$ with analysis of median PFS and 1-year PFS for each variable. Age under 40 years was statistically significant for worse PFS with a median of 7.7 months (95\% CI: $1.5,18.6)$ compared with 24.9 months (95\% CI: $1.1,33.2)$ for age over 40 years patients $(p=0.03)$. - Fig. 2 contains Kaplan-Meier curves from time of initial diagnosis representing the entire study. All patients in this selected cohort had locally recurrent disease with a median PFS of 17.7 months (95\% CI: 4.9, 22.6). Median overall survival was not reached, but 1-year, 2-year, and 5-year estimates were all above $90 \%$. A total of six patients died in our cohort. One patient died of local progression of tumor causing brainstem herniation. One patient died of stroke, unrelated to disease progression or treatment complication. Four patients died outside of our institution, with dates of death obtained from public records. A Swimmer's Plot shows a visual representation of all treatments received by this population in - Fig. 3. A Venn Diagram shows the types of salvage therapies in - Fig. 4.

\section{Salvage Surgery for Locally Recurrent Skull Base Chordomas}

Eleven patients underwent 15 salvage surgery procedures for locally recurrent disease. All failures were within the skull base. - Table 2 shows a summary of each salvage surgery treatment. Three operations were followed by adjuvant radiation. Only two 


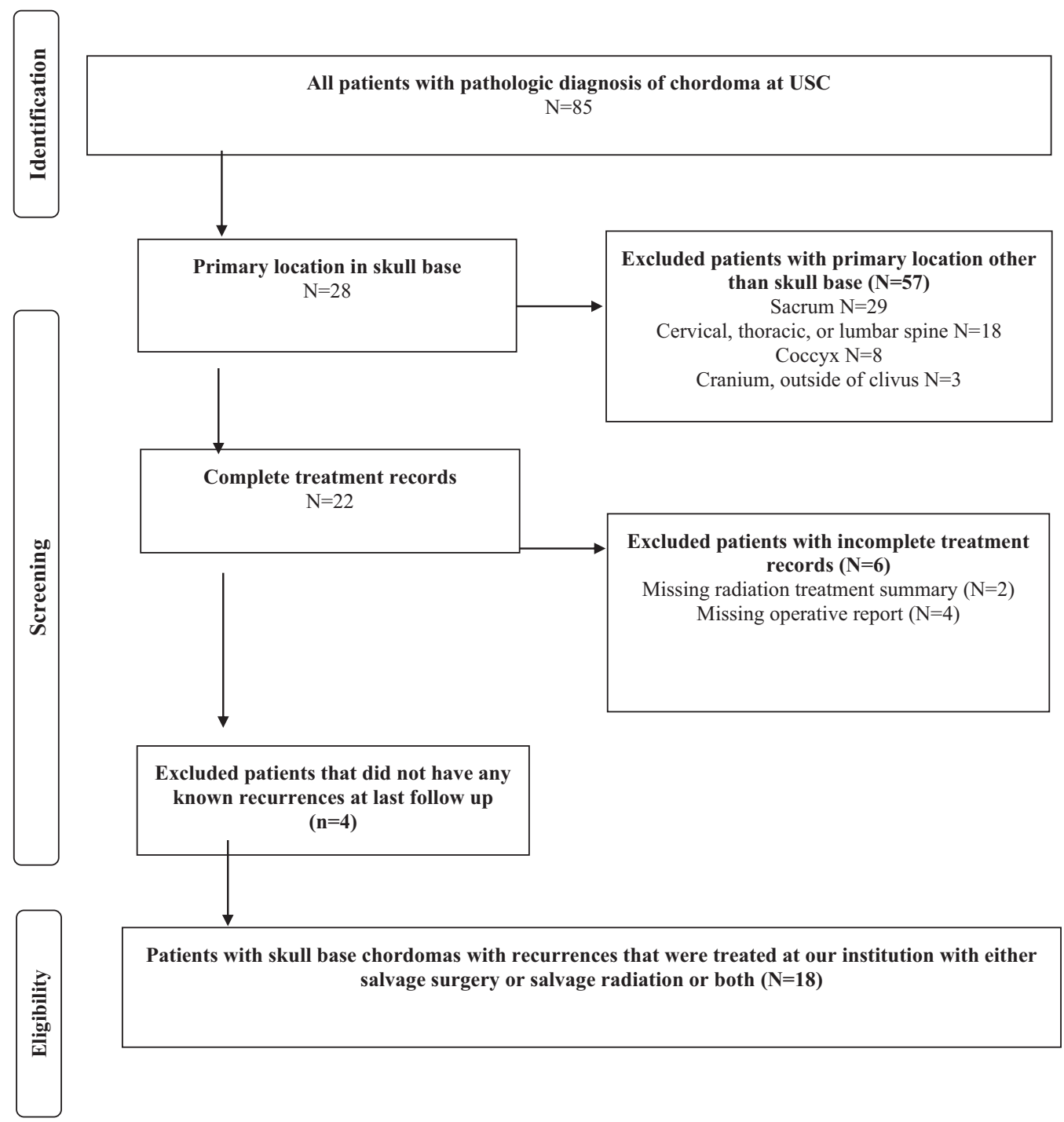

Fig. 1 Consort diagram representing selection and screening of patient cohort.

operations achieved GTR. Surgical technique included: endonasal $(N=6)$ or craniotomy $(N=9)$. Operative reports detailed abutment or invasion of critical structures during the procedure, including the cavernous sinus $(N=3)$, foramen magnum $(N=3)$, sphenoid sinus $(N=3)$, and jugular foramen $(N=3)$. Median tumor volume was $18.9 \mathrm{~cm}^{3}$ (range 1.0-45.4). For this cohort, median PFS from time of surgical resection was 59.2 months (95\% Cl: 4.0, 99.3 months), 2-year PFS was $54.5 \% \pm 10.7 \%$, and 5-year PFS was $35.3 \% \pm 11.2 \%$ (-Fig. 5A). On univariate linear regression, larger tumor volume was statistically significant for shorter PFS $(p=0.02)$, but was not significant on multivariate analysis with backward elimination when patient gender, age, surgical technique, and adjuvant radiation were included. Five patients had another recurrence after salvage surgery while seven had stable disease until death or follow-up.

\section{Salvage Radiation Treatment for Locally Recurrent Skull Base Chordomas}

- Table 3 details the 16 radiotherapy courses underwent by 12 patients for local recurrence. All sites of failure occurred within the skull base. GKRS was the most common modality utilized $(N=9)$ followed by CKRS $(N=5)$ and intensity-modulated radiation therapy $(N=2)$. The median GKRS dose was $16 \mathrm{~Gy}$ (range 16-20 Gy) prescribed to the $50 \%$ isodose line (IDL). Median tumor volume was $2.9 \mathrm{~cm}^{3}$ (range $0.48-16.1$ ). Median PFS from time of salvage radiotherapy was 58.4 months (95\% CI: 25.9-194.5 months), 2-year PFS was 93.6\% $\pm 5.5 \%$, and 5-year PFS was $61.2 \% \pm 12.4 \%$ (-Fig. 5B). No prognostic factors, including gender, age, surgery followed by adjuvant radiation, i.e., SRT (surgery followed by adjuvant radiation) versus RT alone, tumor volume, or radiation dose were significant for PFS on univariate analysis. Six patients who underwent salvage radiotherapy ultimately developed additional recurrence, and 10 salvaged $\mathrm{RT}$ patients remained stable until death or follow-up. A log-rank test comparison of salvage surgery versus salvage radiotherapy was not statistically significant for PFS $(p=0.33)$. For all salvage treatments, including surgery and radiation, the median PFS was 58.4 months (95\% CI: 25.9.0-98.4 months), 2-year PFS was 60.6\% $\pm 8.1 \%$, and 5-year PFS was $40.6 \% \pm 9.2 \%$ (-Fig. 5C) from time of salvage treatment. 
Table 1 Progression-free survival after initial treatment for total population

\begin{tabular}{|c|c|c|c|c|}
\hline & $N$ & $\begin{array}{l}\text { Median PFS in } \\
\text { months }(95 \% \mathrm{Cl})\end{array}$ & $\begin{array}{l}\text { 1-year probability } \\
\text { of PFS }\end{array}$ & $p$-Value \\
\hline Total & $18(100 \%)$ & $17.7(4.9,22.6)$ & $51.1 \% \pm 8.1 \%$ & \\
\hline Gender & & & & 0.36 \\
\hline Male & $7(38.9 \%)$ & $20.7(1.5,33.2)$ & $56.9 \% \pm 12.1 \%$ & \\
\hline Female & $11(61.1 \%)$ & $17.1(3.4,22.6)$ & $46.6 \% \pm 10.7 \%$ & \\
\hline Age at diagnosis & & & & $0.028^{\mathrm{a}}$ \\
\hline Age $<40$ & $8(44.4 \%)$ & $7.7(1.5,18.6)$ & $31.3 \% \pm 12.9 \%$ & \\
\hline Age $\geq 40$ & $10(55.6 \%)$ & $24.9(1.1,33.2)$ & $60.6 \% \pm 9.6 \%$ & \\
\hline Tumor location in clivus & & & & 0.44 \\
\hline Upper & $9(50 \%)$ & $17.1(4.0,20.8)$ & $43.2 \% \pm 12.1 \%$ & \\
\hline Middle & $3(16.7 \%)$ & $29.0(6.3,33.2)$ & $59.1 \% \pm 17.9 \%$ & \\
\hline Lower & $6(33.3 \%)$ & $13.0(1.1,52.5)$ & $56.1 \% \pm 13.2 \%$ & \\
\hline \multicolumn{5}{|l|}{ Presenting symptoms } \\
\hline Visual changes, including diplopia & $6(33.3 \%)$ & $12.7(4.0,29.8)$ & $46.6 \% \pm 14.5 \%$ & 0.56 \\
\hline Cranial neuropathy, including V, VIII, X, XII & $6(33.3 \%)$ & $20.4(1.1,43.6)$ & $55.5 \% \pm 13.3 \%$ & 0.71 \\
\hline Headaches & $2(11.1 \%)$ & $35.6(18.6,52.5)$ & $71 . \% \pm 17.0 \%$ & - \\
\hline Neck pain & $2(11.1 \%)$ & $4.3(1.5,7.2)$ & $6.5 \% \pm 12.5 \%$ & - \\
\hline Nasal obstruction & $1(5.6 \%)$ & 4.9 & $8.7 \% \pm 21.4 \%$ & - \\
\hline \multicolumn{5}{|l|}{$\begin{array}{l}\text { Abutment or involvement of } \\
\text { neighboring structures }\end{array}$} \\
\hline Brainstem & $5(27.8 \%)$ & $4.0(1.5,29.8)$ & $27.0 \% \pm 15.8 \%$ & 0.11 \\
\hline Cavernous sinus & $3(16.7 \%)$ & $33.2(7.2,43.6)$ & $65.2 \% \pm 16.1 \%$ & 0.27 \\
\hline Sphenoid sinus & $7(38.9 \%)$ & $8.2(4.9,29.0)$ & $44.4 \% \pm 13.6 \%$ & 0.45 \\
\hline Sella turcica & $2(11.1 \%)$ & $34.8(17.1,52.5)$ & $70.8 \% \pm 17.2 \%$ & - \\
\hline Initial treatment & & & & 0.97 \\
\hline Surgery & $11(61.1 \%)$ & $18.2(4.0,29.0)$ & $52.9 \% \pm 10.2 \%$ & \\
\hline Surgery with adjuvant radiation & $7(38.9 \%)$ & $6.3(1.1,29.8)$ & $48.1 \% \pm 13.3 \%$ & \\
\hline Initial surgery resection & & & & 0.87 \\
\hline GTR & $3(16.7 \%)$ & $18.2(8.2,29.0)$ & $52.2 \% \pm 19.6 \%$ & \\
\hline STR & $15(83.3 \%)$ & $17.1(3.3,22.6)$ & $50.9 \% \pm 8.9 \%$ & \\
\hline \multicolumn{5}{|l|}{ Initial radiation characteristics } \\
\hline GKRS & $5(71.4 \%)$ & $6.3(1.1,29.8)$ & $37.3 \% \pm 16.5 \%$ & \\
\hline IMRT & $1(14.3 \%)$ & 1.5 & $0.04 \% \pm 0.3 \%$ & \\
\hline Protons & $1(14.3 \%)$ & 52.5 & $79.6 \% \pm 18.2 \%$ & \\
\hline
\end{tabular}

Abbreviations: Cl, confidence interval; GKRS, gamma knife radiosurgery; GTR, gross total resection; IMRT, intensity-modulated radiation therapy; PFS, progression-free survival.

${ }^{a}$ Denotes statistical significance with univariate log-rank test.

\section{Phone Interview Follow-Up}

Eight out of 12 living patients were available and provided informed consent. Their results are summarized in - Table 4. Tinnitus was reported by two patients, while headaches, visual field deficits, hearing loss, anosmia, dysphagia, and memory loss had a frequency of one patient.

\section{Representative Case of a Patient with Four Courses of Treatment}

A 48-year-old woman presented with 3 weeks of acute-onset diplopia with magnetic resonance imaging of the brain revealing an erosive lesion involving the mid clivus, extending into the sphenoid sinus with abutment of the brainstem at the level of the pons. Shortly after her diagnosis, she underwent endoscopic endonasal transsphenoidal approach for STR, with microdissection and fat graft to the tumor bed. She received adjuvant radiation 4 months after her surgery with GKRS $15 \mathrm{~Gy}$ prescribed to the 50\% IDL to a residual tumor volume of $3.1 \mathrm{~cm}^{3}$ utilizing seven shots. She recurred after 25 months with a 1-cm suprasellar mass arising from the dorsum sellae and underwent a second course of GKRS with a dose of 16 Gy prescribed to the 50\% IDL to a tumor 


\section{OVERALL SURVIVAL}

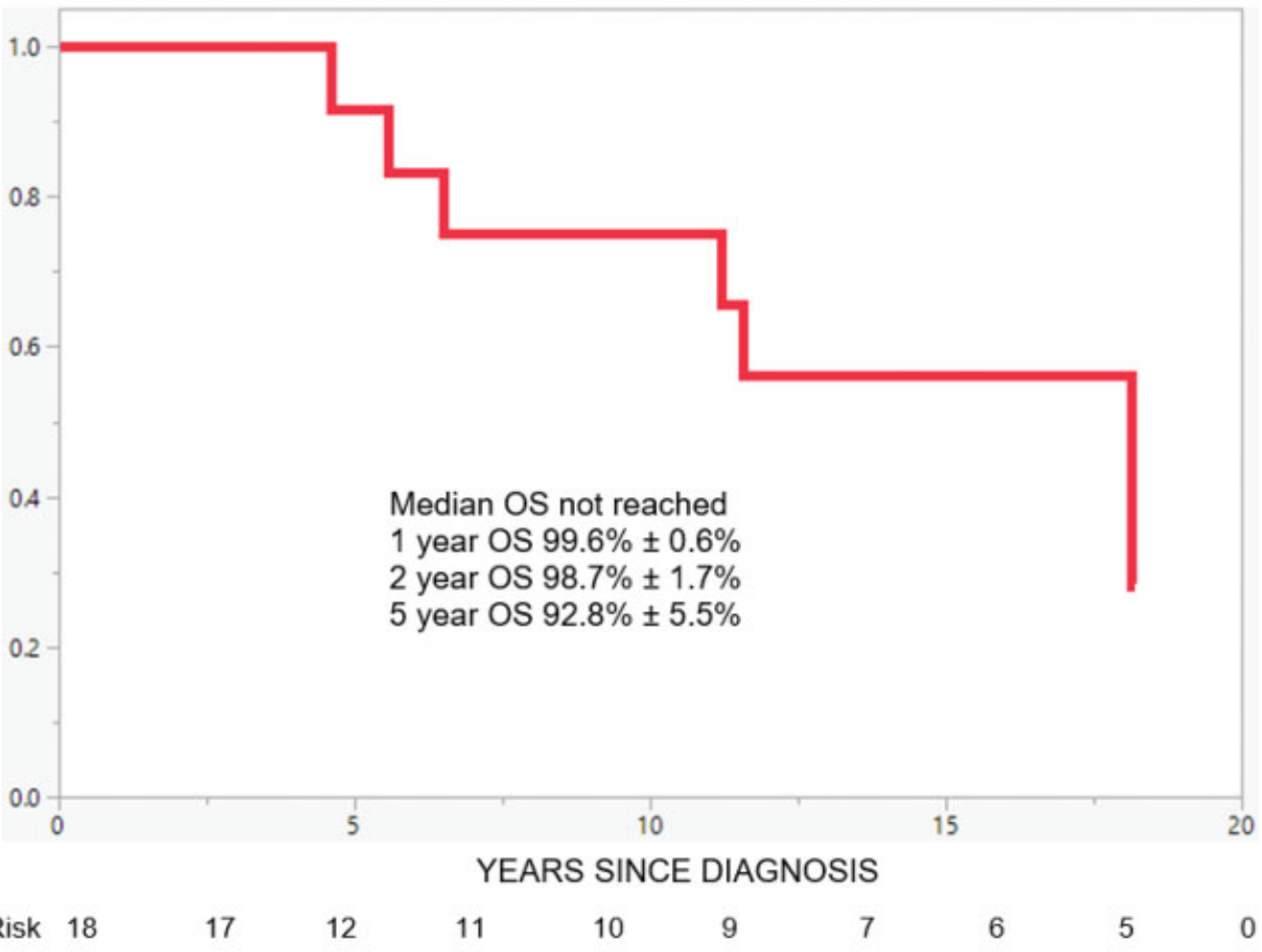

PROGRESSION-FREE SURVIVAL

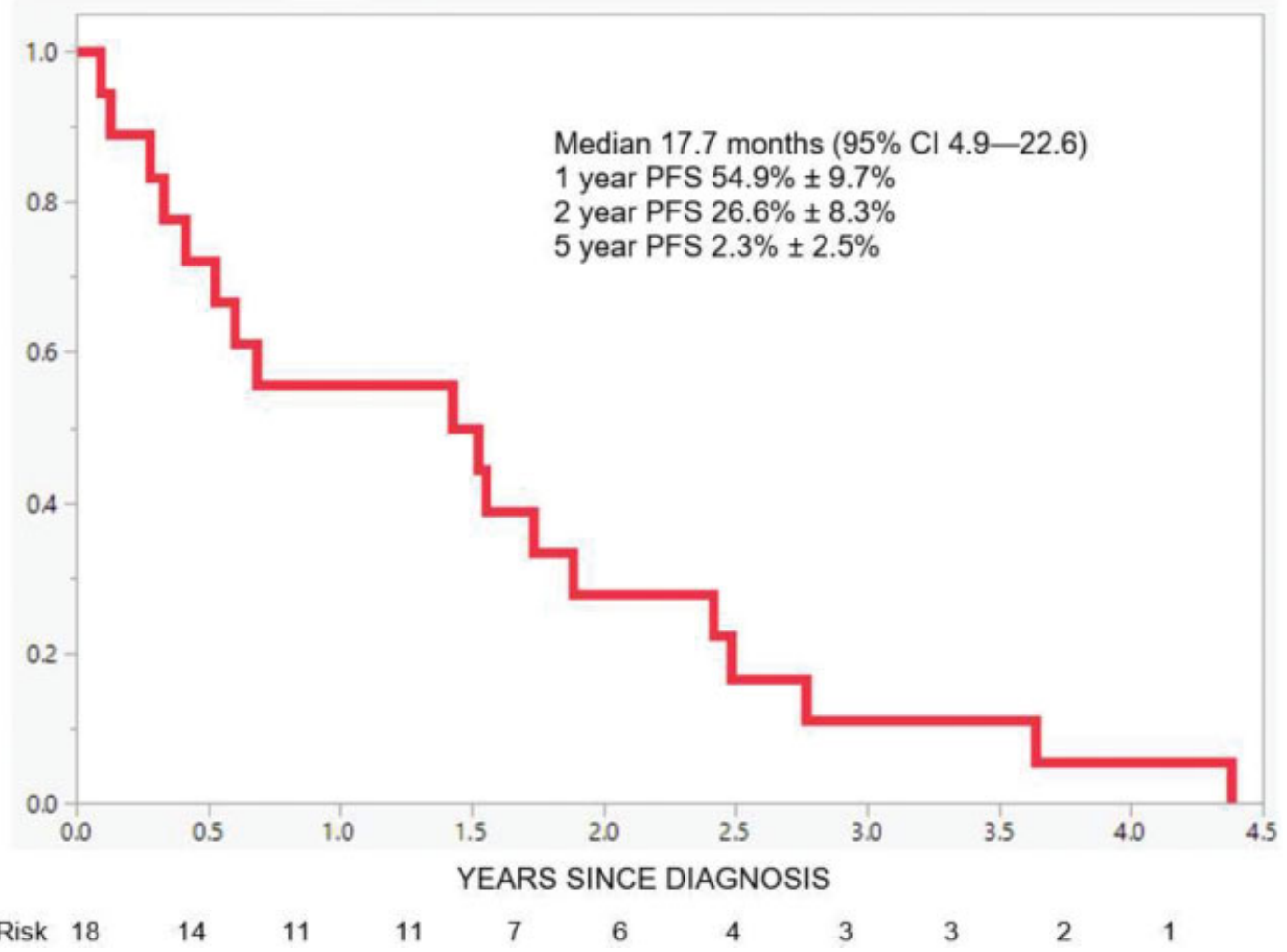

Fig. 2 Kaplan-Meier curves for overall survival and progression-free survival for total population. (A) Overall survival from time of diagnosis with median not reached in this population, 1 -year overall survival $99.6 \% \pm 0.6 \%, 2$-year overall survival $98.7 \% \pm 1.7 \%$, 5 -year overall survival $92.8 \% \pm 5.5 \%$. (B) Progression-free survival from time of diagnosis to first progression with median of 17.7 months (95\% Cl: $4.9-22.6$ months), 1-year PFS 54.9\% \pm 9.7\%, 2-year local control 26.6\% $\pm 8.3 \%$, 5-year PFS 2.3\% $\pm 2.5 \%$. (C) Age $\geq 40$ has longer PFS (median 24.8 months, $95 \% \mathrm{Cl}$ : 1.1-33.2 months) compared with age $<40$ (median 7.7 months, $95 \% \mathrm{Cl}: 1.5-18.6$ months) with $p=0.03$. Cl, confidence interval; PFS, progression-free survival. 
PROGRESSION-FREE SURVIVAL BY AGE

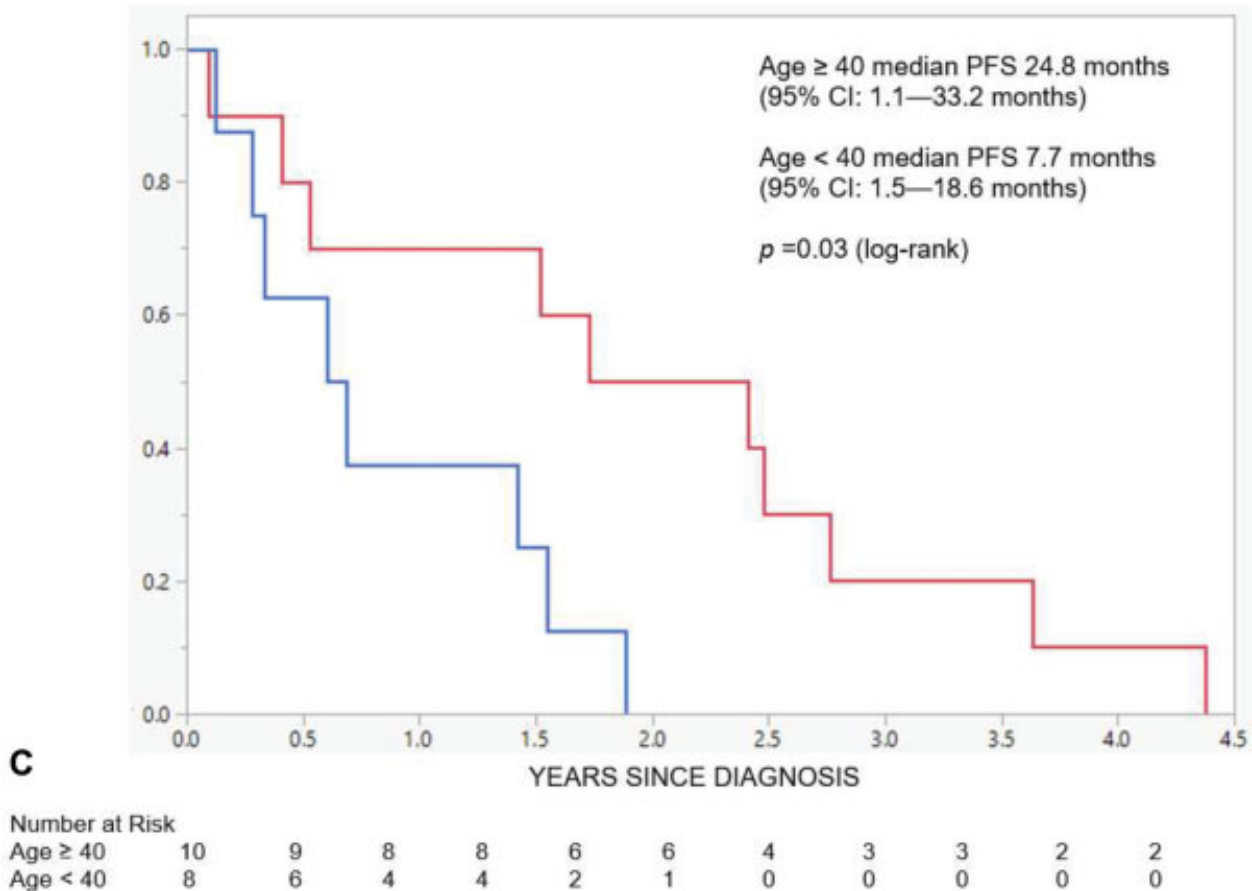

Fig. 2 (Continued)

\section{Swimmer's Plot of Recurrent Chordoma Patients $(\mathrm{N}=18)$ Years since Diagnosis}

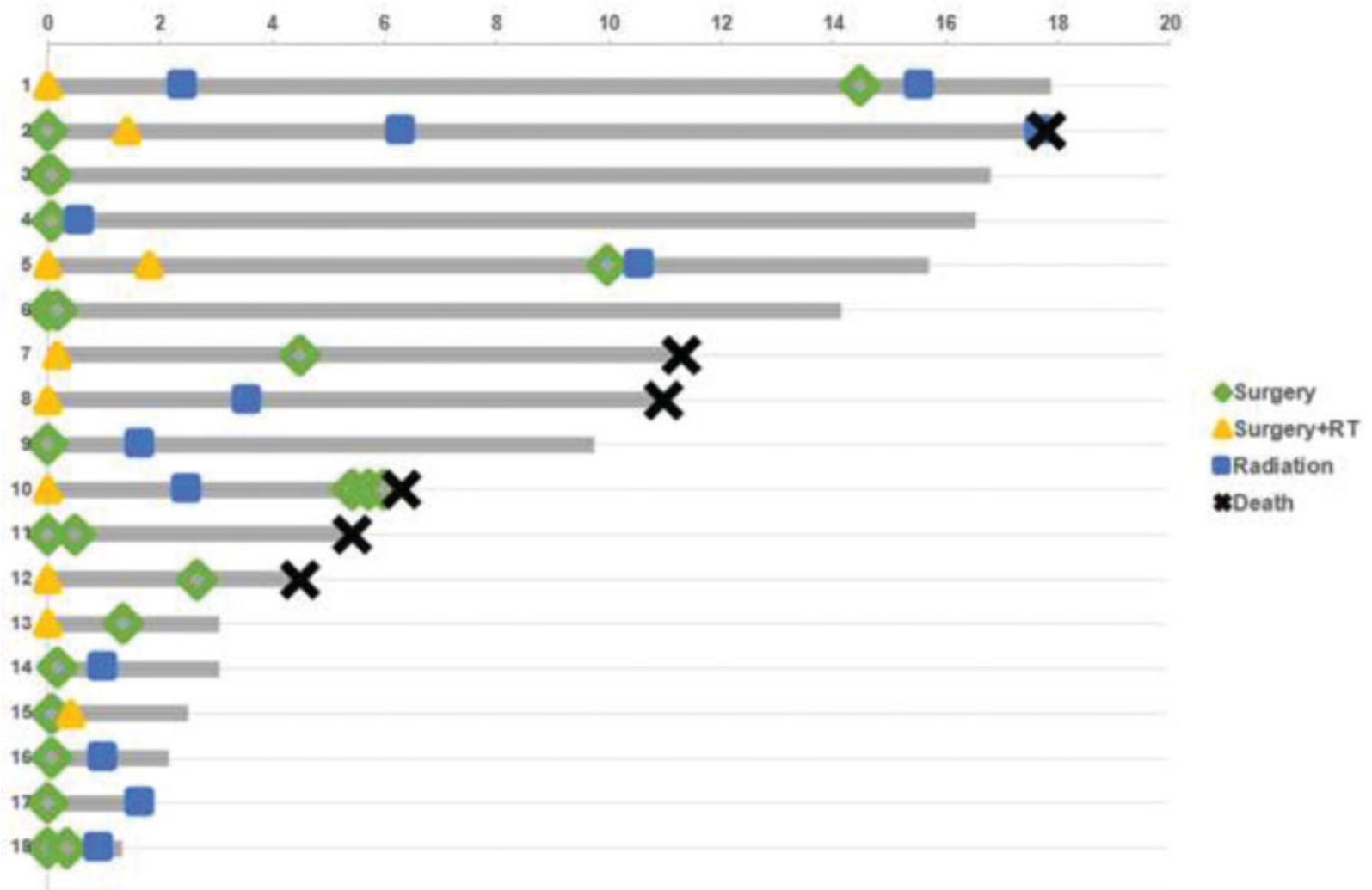

Fig. 3 Swimmer's plot of Individual chordoma patients. Bar length indicates duration of follow-up shown in months after time of initial diagnosis. $X$ marks time point of death while others denote interventions (diamond = surgery alone, triangle = surgery followed by adjuvant radiation, square $=$ radiation alone). 


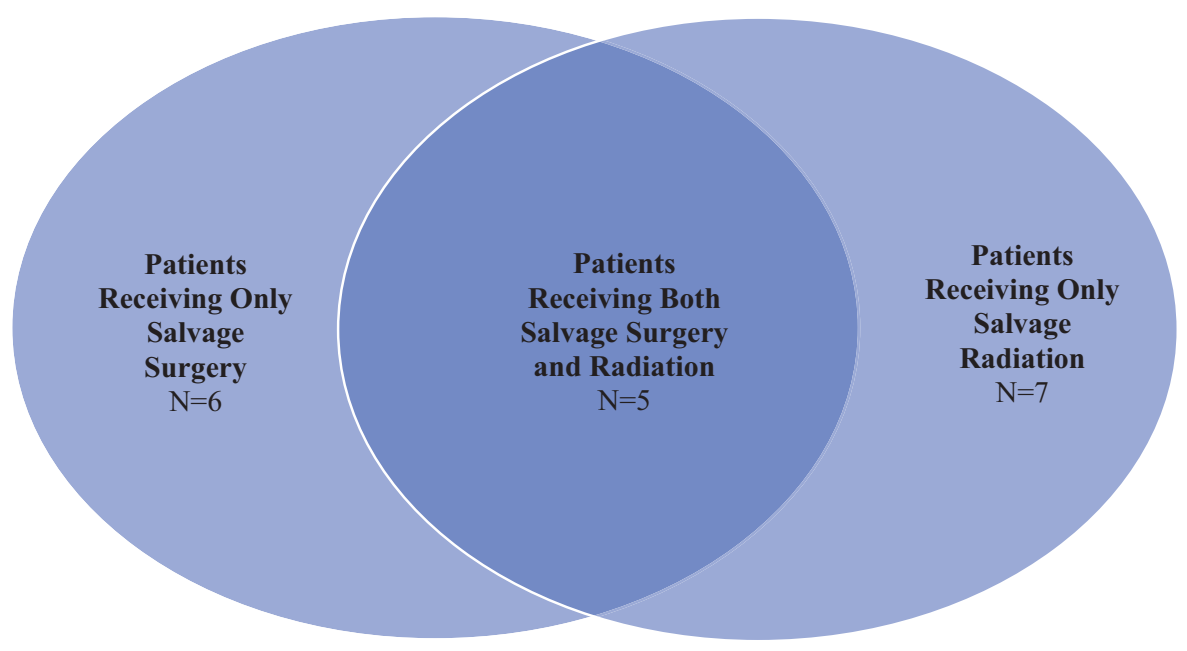

Fig. 4 Venn-diagram of salvage treatments for total cohort.

volume of $1.9 \mathrm{~cm}^{3}$ utilizing nine shots. She recurred again after 25.9 months with a left-sided clival mass that surrounds the internal carotid artery and underwent her second surgery, achieving a GTR with an extended endoscopic endonasal transclival approach. Unfortunately, she had a third local recurrence 12.8 months after this surgery with progressive growth of a left-sided lesion in the postoperative bed ( 9 by $8 \mathrm{~mm}$ to 15 by $11 \mathrm{~mm}$ in 12 months) and received a third course of GKRS of 18 Gy prescribed to the $50 \%$ IDL to a tumor volume of $1.09 \mathrm{~cm}^{3}$ utilizing 15 shots. She remained stable with surveillance imaging follow-up 147.5 months after her last GKRS (215 months after her initial diagnosis). This patient is represented as case number 1 in - Tables 2 and 3.

\section{Literature Review}

Excluding review articles and abstracts, a total of 64 peerreviewed publications were identified and examined. Of these, 29 articles only reported experience with initial management after diagnosis and 24 studies included salvage treatments without reporting outcomes for the recurrent subpopulation. The details of the remaining 11 articles regarding salvage therapy for skull base chordomas are summarized in - Table 5 . $^{11-21}$

\section{Discussion}

Locally recurrent skull base chordomas present a challenging treatment dilemma due to considerations such as postoperative changes (e.g., scar tissue, adhesions, or friable anatomy) or radiation dose constraints from prior therapies. In our report, we had reasonable overall survival outcomes despite multiple recurrences due to effective salvage therapies. Median PFS after surgical re-resection or radiotherapy treatments was comparable to those reported in literature ( $\mathbf{- T a b l e ~} \mathbf{5}$ ).

Our initial PFS was low in our population, but this is largely due to selection bias as we only included patients who experienced recurrences. Our median PFS of 17.7 months was in fact comparable to or longer than other reports that included only relapsed patients. ${ }^{11,18}$ On univariate analysis, older patients had better PFS, which is incongruent with some studies which showed younger age is usually a positive prognostic factor. ${ }^{20,26-28}$ However, some publications showed no correlation with age ${ }^{11,29-31}$ while others showed older age had better outcomes. ${ }^{32,33}$ In our analysis, this correlation did not stay significant on multivariate analysis and may be due to other confounding factors in our population. It is also difficult to make definitive conclusions with such small numbers.

For patients treated with salvage surgical re-resection, larger tumor volume was associated with worse PFS. Many other studies showed the same correlation. ${ }^{26,28,34,35}$ Larger tumor sizes may lead to more complicated and difficult surgeries, more likelihood of proximity to eloquent structures, and suboptimal debulking. This correlation was not seen with radiotherapy, likely due to the selection bias for smaller tumors when delivering SRS. The sample size of our cohort is too small to make any conclusions regarding the comparison of these treatment modalities. In our multidisciplinary practice, the decision for either modality is usually informed by tumor size and location with SRS usually reserved for those smaller tumors with adequate distance from critical structures, and surgical resection recommended for more technically challenging lesions.

Our cohort experienced mild or no long-term toxicity, in line with other experiences using SRS. ${ }^{13,15}$ More detailed treatment information such as overlapping fields, elapsed time between treatments, total biological equivalent dose, and concurrent use of systemic therapies is needed before making assumptions regarding dose response for toxicity.

The limitations of this study include its small cohort, retrospective nature, and lack of consistent long-term follow-up. Given that many patients had treatments that spanned several decades, there is heterogeneity in delivered therapies due to changing philosophies and techniques. Some older treatments had incomplete data due to inadequate electronic record keeping. Incomplete follow-up after benign diseases compared with malignant pathologies has 


\begin{tabular}{|c|c|c|c|c|c|c|c|c|c|c|c|c|c|c|c|}
\hline 离 & & & & 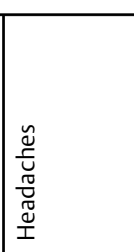 & 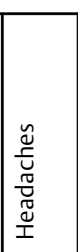 & 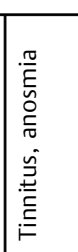 & & & & & & & & & 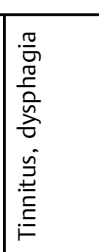 \\
\hline 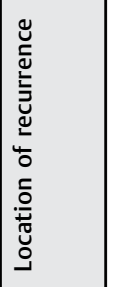 & 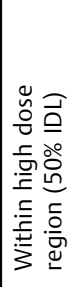 & 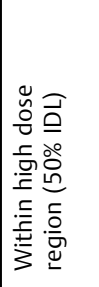 & & 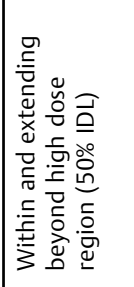 & 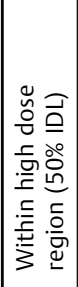 & & & 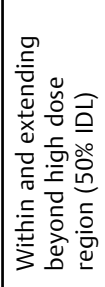 & 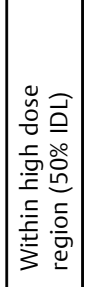 & 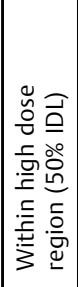 & & & & & 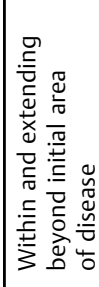 \\
\hline 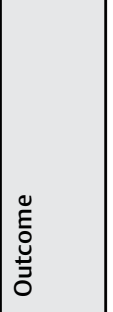 & 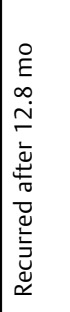 & 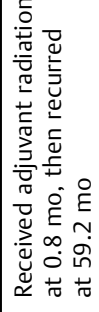 & 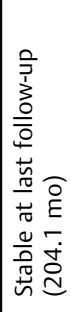 & 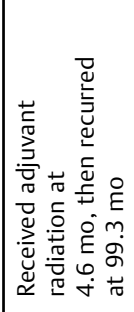 & 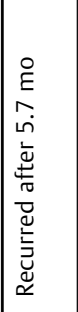 & 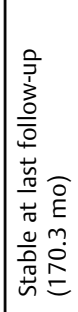 & 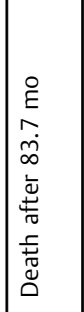 & 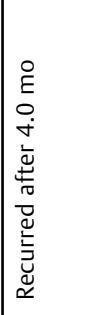 & 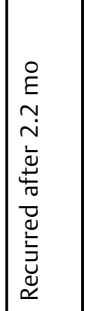 & 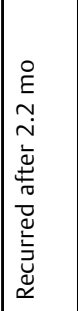 & 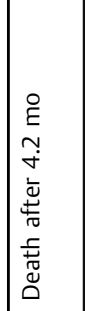 & 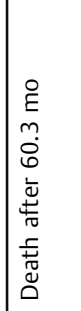 & 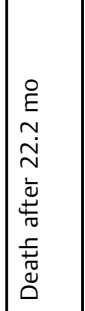 & 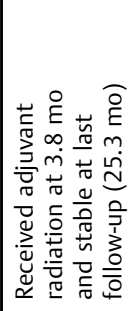 & 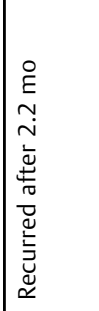 \\
\hline 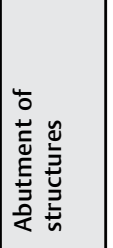 & 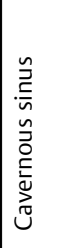 & 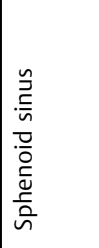 & 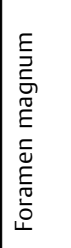 & 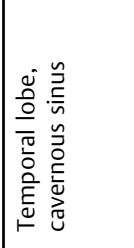 & 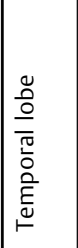 & 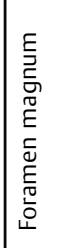 & 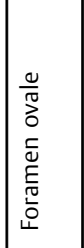 & 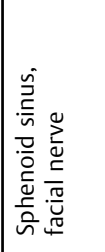 & 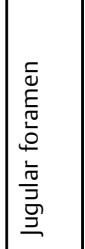 & 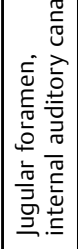 & 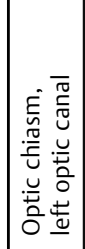 & 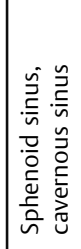 & 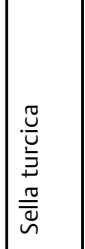 & $\mid \begin{array}{l}0 \\
\stackrel{0}{0} \\
2\end{array}$ & 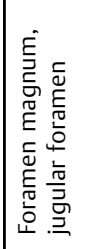 \\
\hline 窟 & 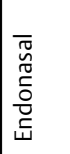 & 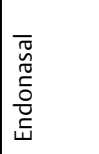 & 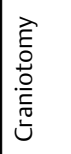 & 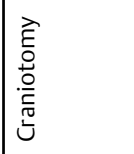 & 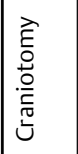 & 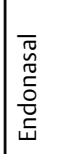 & 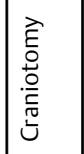 & 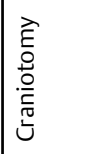 & 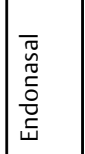 & 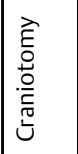 & 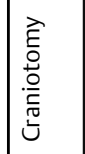 & 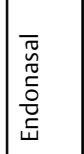 & 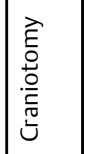 & 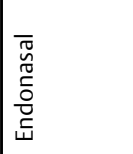 & 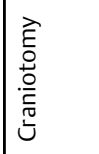 \\
\hline 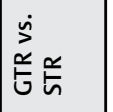 & $\stackrel{0}{\omega}$ & 畜 & $\stackrel{0}{\omega}$ & 䋨 & 品 & 受 & 总 & $\underline{\underline{n}}$ & 总 & 兑 & 总 & 兰 & 畜 & 糹 & 兽 \\
\hline 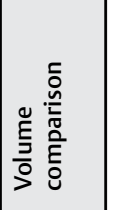 & 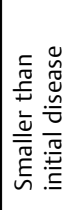 & & & & 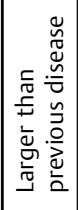 & 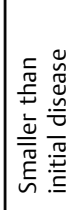 & 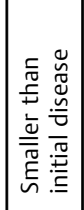 & 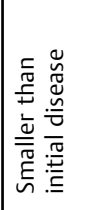 & 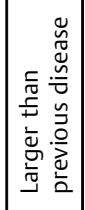 & 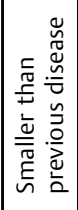 & & 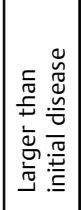 & 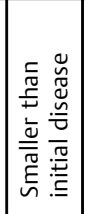 & 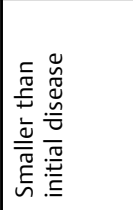 & 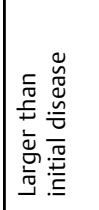 \\
\hline 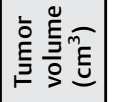 & $\approx$ & $\frac{s}{z}$ & $\frac{s}{z}$ & $\frac{\pi}{z}$ & $\begin{array}{l}\stackrel{0}{\sim} \\
\ddot{\sim}\end{array}$ & $\stackrel{\text { I }}{\stackrel{1}{r}}$ & $\stackrel{?}{?}$ & $\begin{array}{l}\stackrel{0}{0} \\
\stackrel{\infty}{-}\end{array}$ & $\stackrel{\stackrel{m}{\sim}}{\stackrel{\sim}{\sim}}$ & 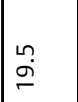 & $\frac{s}{z}$ & O̊. & $\stackrel{\sim}{m}$ & $\stackrel{\circ}{-}$ & 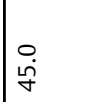 \\
\hline $\begin{array}{l}\stackrel{x}{\longmapsto} \\
\stackrel{\bar{c}}{\underline{L}}\end{array}$ & $\begin{array}{l}\llcorner \\
\stackrel{-}{\omega} \\
\stackrel{\alpha}{\sim}\end{array}$ & $\begin{array}{l}\bar{v} \\
\tilde{w} \\
v\end{array}$ & n & 鸴 & 总点 & $\backsim$ & $\backsim$ & $\begin{array}{l}\frac{a}{\alpha} \\
\stackrel{-}{\sim} \\
\sim\end{array}$ & 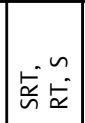 & 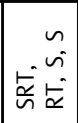 & $n$ & $n$ & 点 & n & n \\
\hline $\begin{array}{l}\dot{s}= \\
\dot{n} 心\end{array}$ & $\backsim$ & 学 & n & 点 & $n$ & $n$ & $n$ & $n$ & $\backsim$ & $n$ & $n$ & $n$ & $n$ & 鿖 & n \\
\hline 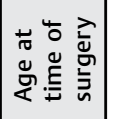 & $\tilde{\varphi}$ & ठ & $\bar{m}$ & $\stackrel{\mathscr{n}}{m}$ & $\dddot{q}$ & F & f & g & g & g & in & 6 & m & i) & $\stackrel{0}{m}$ \\
\hline 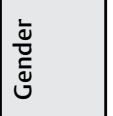 & 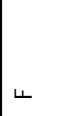 & 4 & $\Sigma$ & 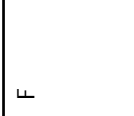 & 4 & 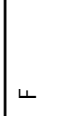 & $\Sigma$ & $\Sigma$ & $\Sigma$ & $\Sigma$ & 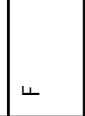 & $\Sigma$ & 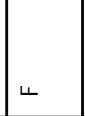 & $\Sigma$ & 4 \\
\hline $\begin{array}{l}\text { \# } \\
\text { 崩 } \\
\text { 心 }\end{array}$ & - & $\sim$ & $m$ & ก๊ & in & 0 & n & $\stackrel{\pi}{\circ}$ & 음 & $\stackrel{\circ}{\circ}$ & $=$ & $\simeq$ & $m$ & $\stackrel{n}{\longrightarrow}$ & $\cong$ \\
\hline
\end{tabular}




\section{PROGRESSION-FREE SURVIVAL AFTER SALVAGE SURGERY}

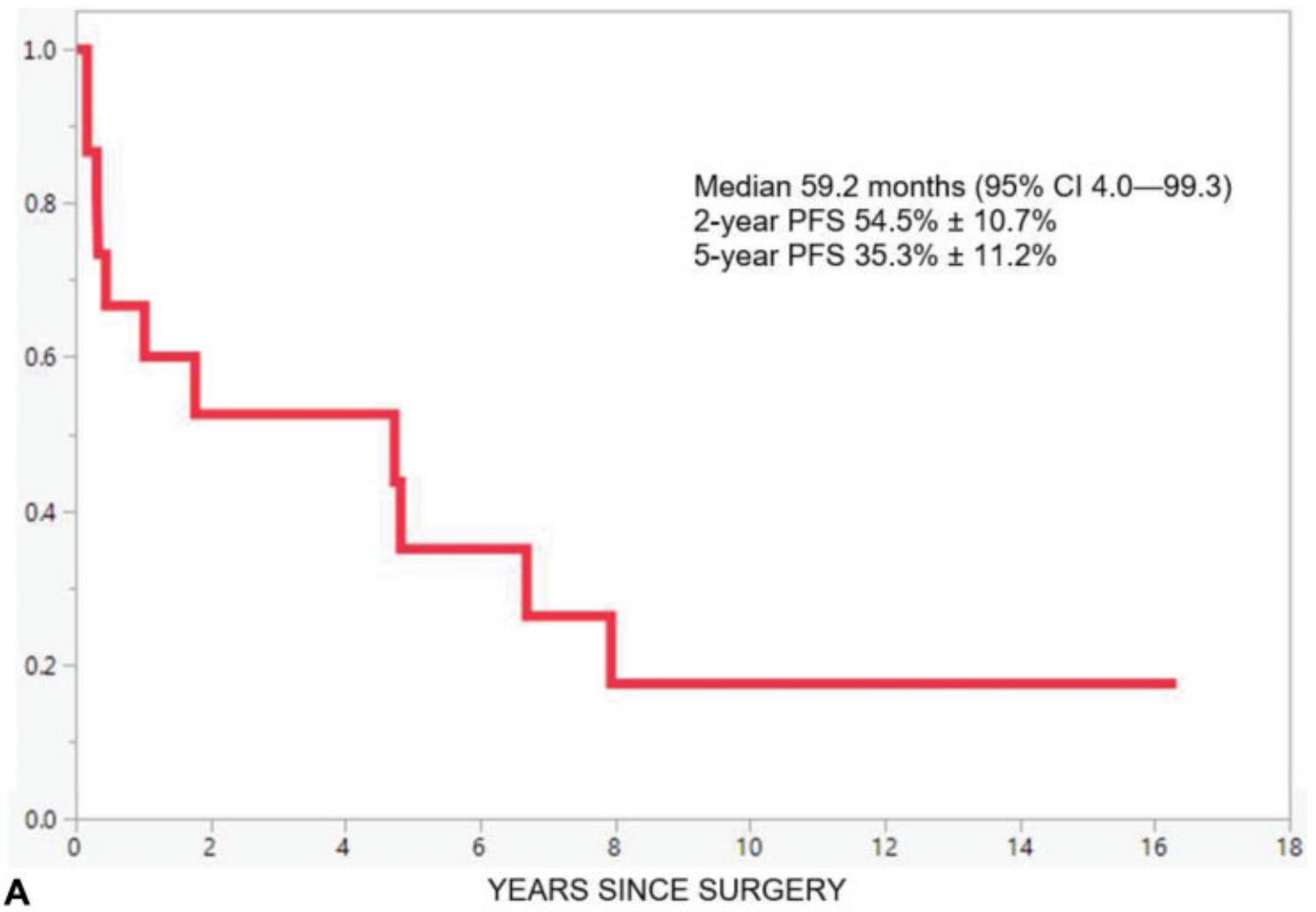

PROGRESSION-FREE SURVIVAL AFTER SALVAGE RADIATION

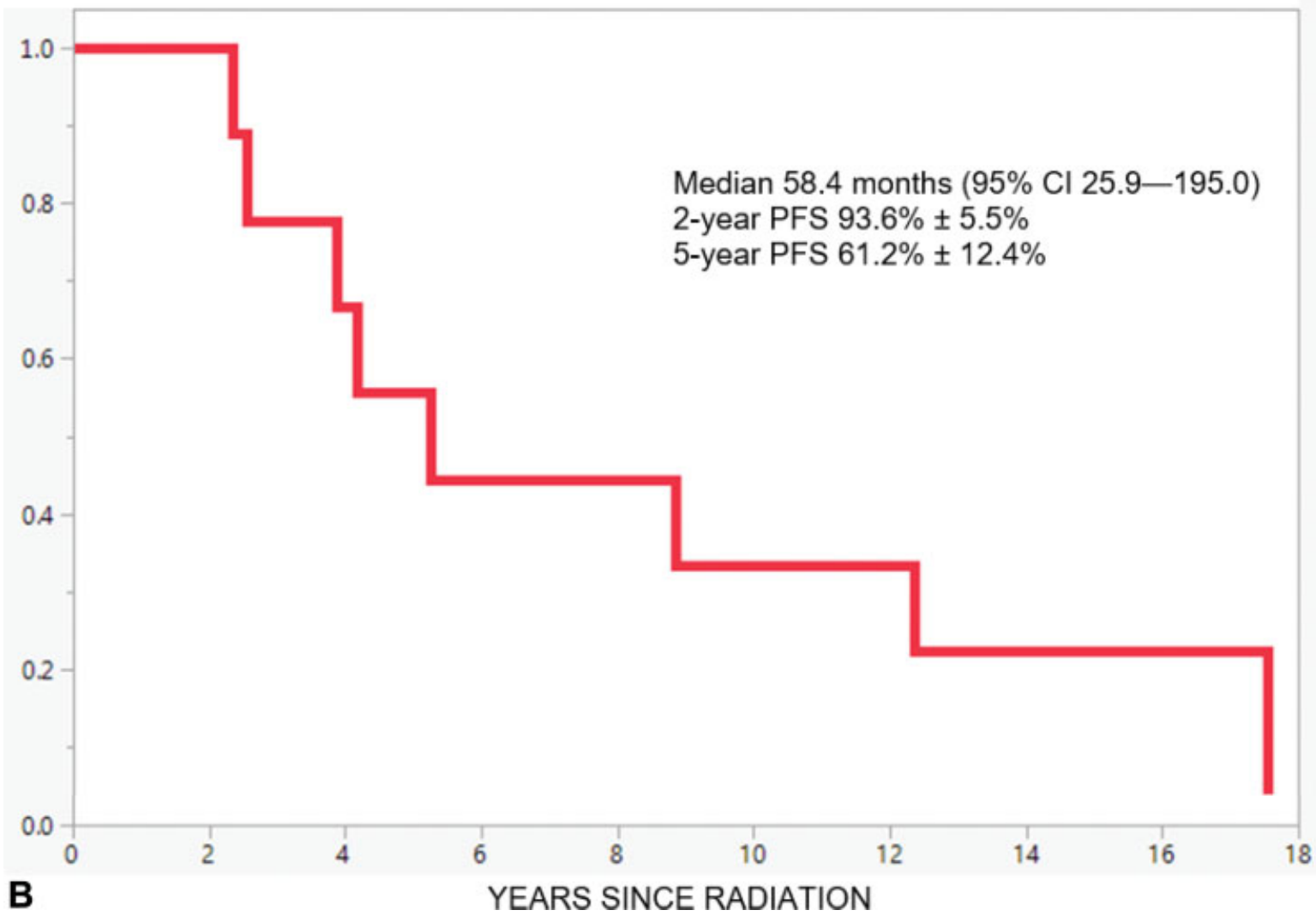

Fig. 5 Kaplan-Meier plots for salvage treatments for locally recurrent skull base chordomas. (A) PFS for Salvage Surgery Treatments. (B) PFS for salvage radiation treatments. (C) Combined PFS. PFS, progression-free survival. 


\section{COMBINED PROGRESSION-FREE SURVIVAL}

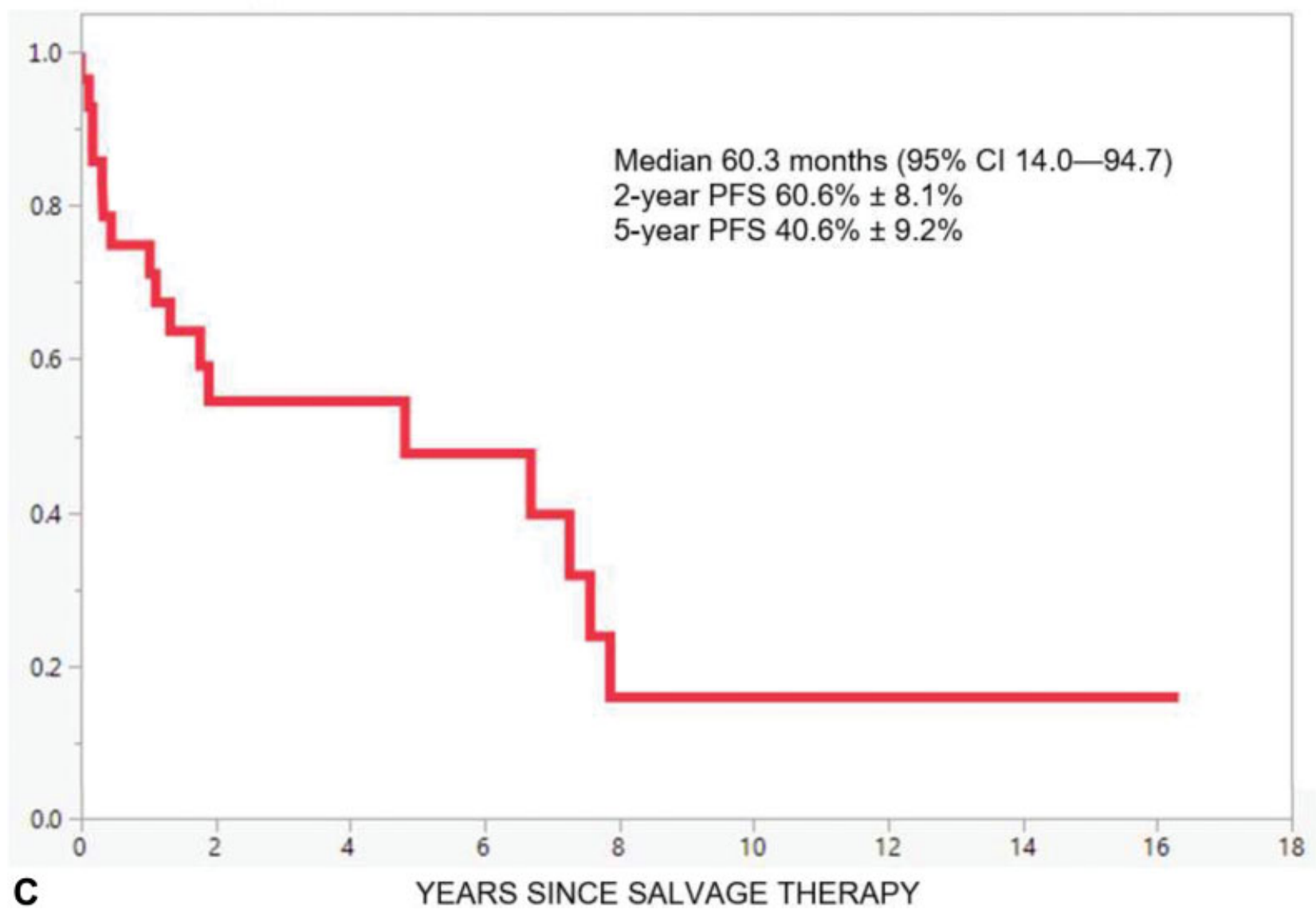

Fig. 5 (Continued)

previously been documented and proved true in our study. ${ }^{36}$ The phone interviews were conducted to compensate for lack of clinic visits, but most patients were unavailable or had expired, and those who answered may be affected by some degree of recall bias. Four patients died outside of our institution, and data on their survival were obtained from public registries, which do not provide the cause of death. Whether the deaths were due to tumor progression or treatment complications would have provided useful insight into our experience with salvage therapies. Due to the benign nature of this disease, there was a general lack of consistent follow-up among patients, and perhaps suggests a need for better patient education regarding the high recurrence rates of chordomas and potential need for additional salvage therapies.

In our review of the current literature on recurrent skull base chordomas, we found reports of other institutions using a wide array of surgical or radiation treatment strategies. Fagundes et al from Harvard University published the earliest report of a large cohort of 45 patients with recurrent skull base chordomas, of which the majority received surgical salvage with GTR only achieved in two patients and a short median interval to progression of 7 months. ${ }^{11}$ Of note, none of these patients received reirradiation. Other reports of primarily surgical salvage using a variety of techniques, including micro- surgical, midline anterior, lateral, and endoscopic approaches, had recurrence rates ranging from 39 to $81 \%{ }^{12,14,19}$ Radiation techniques for salvage therapies included GKRS, CKRS, proton therapy, carbon ion therapy, and LINAC-based SRS with recurrence rates ranging from 36 to $85 \%{ }^{13,15,17,18,20}$ Bugoci et al from Kaiser, Los Angeles described novel therapy using molecular targets, including agents such as Gleevec and Dasatinib, with two out of three patients alive with stable disease after at least 30 months of therapy. ${ }^{16}$ Attempts for meaningful comparisons between these different treatment algorithms are limited due to differences in patient population, tumor characteristics, and reported outcome measures. In general, these cases are challenging and require a multidisciplinary approach with careful and realistic consideration of the limitations of each available modality.

\section{Conclusion}

Our report provides detailed information on salvage surgical or radiation treatment for recurrent/progressive skull base chordomas. This experience, combined with a rigorous literature review, supports the use of salvage therapies with re-resection or high-dose radiation, particularly SRS, as feasible strategies with reasonable outcomes and minimal toxicities when treated at tertiary academic centers. 


\begin{tabular}{|c|c|c|c|c|c|c|c|c|c|c|c|c|c|c|c|c|}
\hline 离 & 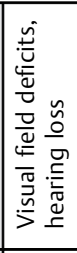 & & & & & & 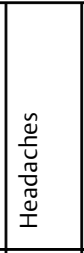 & 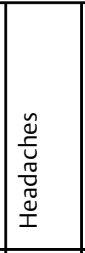 & & & & & & & & 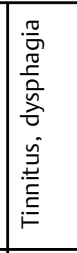 \\
\hline 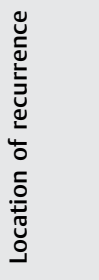 & 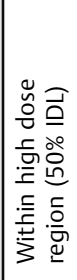 & & 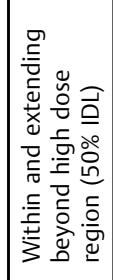 & 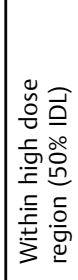 & & & 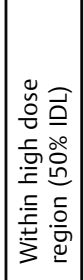 & & & 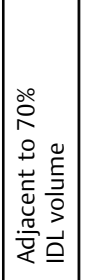 & 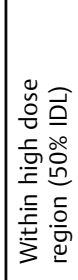 & & & & & \\
\hline 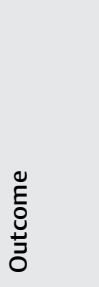 & 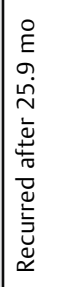 & 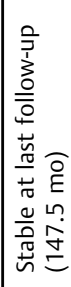 & 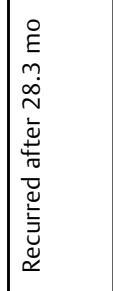 & 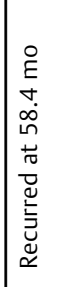 & 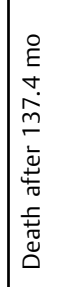 & 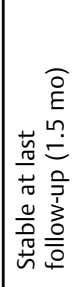 & 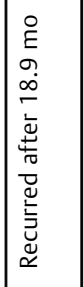 & 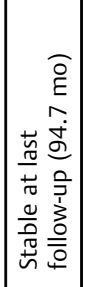 & 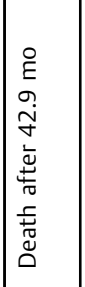 & 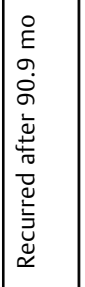 & 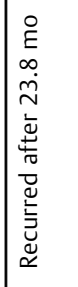 & 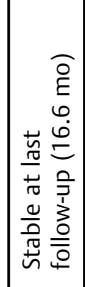 & 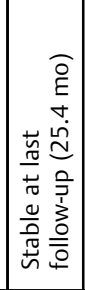 & 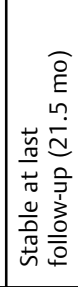 & 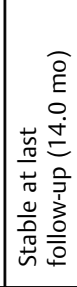 & 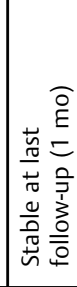 \\
\hline 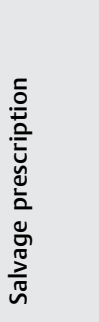 & 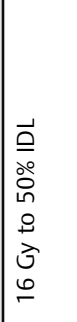 & 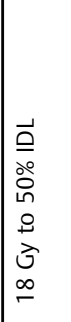 & 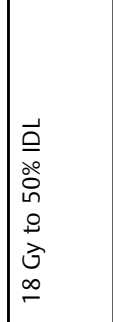 & 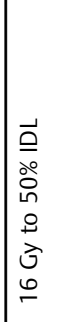 & 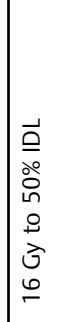 & 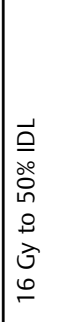 & 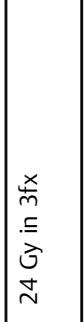 & 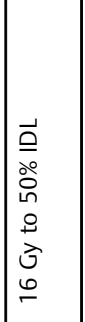 & 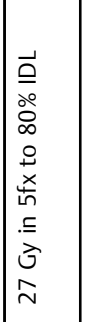 & 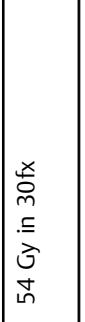 & $\frac{\alpha}{z}$ & 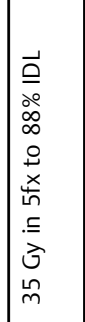 & 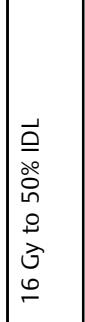 & 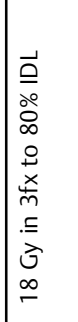 & 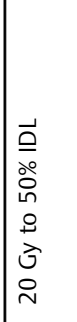 & 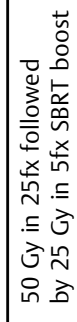 \\
\hline 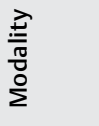 & 芩 & 芩 & \begin{tabular}{|l}
$\tilde{y}$ \\
$\frac{\tilde{v}}{v}$
\end{tabular} & 竎 & $\begin{array}{l}\tilde{y} \\
\frac{\tilde{u}}{v}\end{array}$ & 芩 & 㫕 & $\begin{array}{l}\tilde{y} \\
\frac{\tilde{y}}{v}\end{array}$ & 㫕 & $\stackrel{\stackrel{p}{\underline{\alpha}}}{\underline{\alpha}}$ & 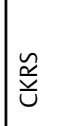 & 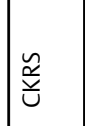 & 竧 & 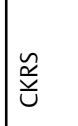 & $\frac{\widetilde{\tilde{v}}}{\mathrm{u}}$ & $\mid \stackrel{e}{\underline{\Sigma}}$ \\
\hline 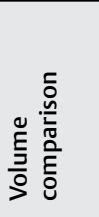 & 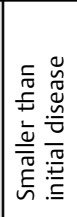 & 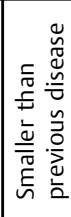 & 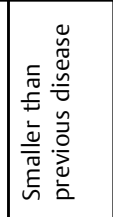 & 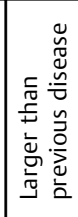 & 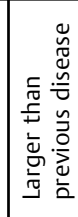 & 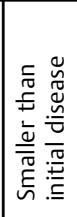 & 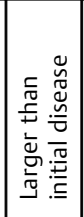 & 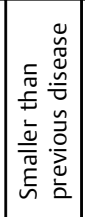 & 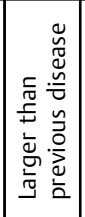 & 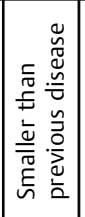 & & 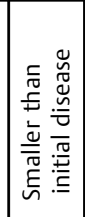 & 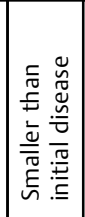 & 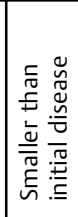 & 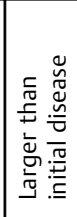 & 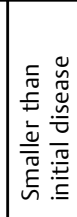 \\
\hline 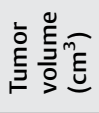 & $\stackrel{?}{\longrightarrow}$ & $F$ & $\stackrel{\sim}{\sim}$ & $a$ & $\tilde{\sigma}$ & $\mid \begin{array}{c}m \\
\infty\end{array}$ & $\stackrel{\text { ํㅜㅁ }}{=}$ & $\mid \begin{array}{l}\infty \\
0 \\
0\end{array}$ & $\ddot{\check{\varphi}}$ & 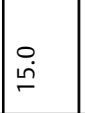 & $\frac{\alpha}{z}$ & fo & 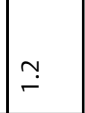 & $\hat{i}$ & $\stackrel{0}{-}$ & $\stackrel{\circ}{\circ}$ \\
\hline $\begin{array}{l}\underset{x}{ } \\
\stackrel{\underline{o}}{\underline{2}}\end{array}$ & 总 & 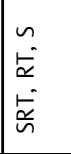 & $\backsim$ & $\mid \begin{array}{l}\text { 幽 } \\
\text { vi }\end{array}$ & 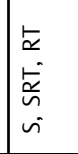 & $n$ & 总 & $\begin{array}{l}n \\
\tilde{w} \\
\tilde{w} \\
\tilde{w} \\
\tilde{v}\end{array}$ & 总 & $\backsim$ & 学 & $n$ & $n$ & $\backsim$ & $\backsim$ & $\backsim$ \\
\hline 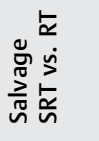 & ta & $\stackrel{\llcorner}{\alpha}$ & 啇 & $\stackrel{\llcorner}{\alpha}$ & $\stackrel{\llcorner}{\alpha}$ & $\stackrel{\llcorner}{\alpha}$ & 商 & $\stackrel{\llcorner}{ }$ & ta & ta & $\stackrel{\llcorner}{\alpha}$ & $\stackrel{\llcorner}{\alpha}$ & 点 & $\stackrel{\llcorner}{\alpha}$ & $\stackrel{\llcorner}{\alpha}$ & \llcorner \\
\hline 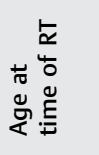 & in & t & ڤి & 이 & $\bar{\infty}$ & $\stackrel{0}{\circ}$ & $\stackrel{0}{m}$ & $\forall$ & g & m & o & 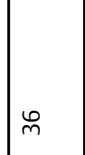 & in & f & $\mathcal{F}$ & $\stackrel{p}{m}$ \\
\hline 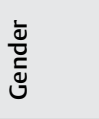 & 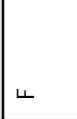 & $\sqcup$ & 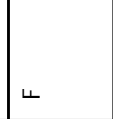 & 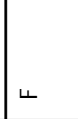 & 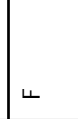 & 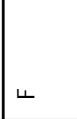 & 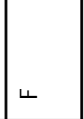 & 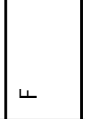 & 4 & 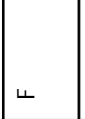 & $\Sigma$ & $\Sigma$ & $\Sigma$ & 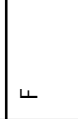 & $\Sigma$ & \llcorner \\
\hline 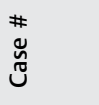 & $\stackrel{0}{0}$ & $\stackrel{2}{2}$ & $\approx$ & $\hat{\sim}$ & $\breve{N}$ & $\nabla$ & ஸ็ & กิ & $\infty$ & $\sigma$ & 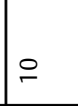 & $\Xi$ & $\stackrel{\text { ㅇ }}{ }$ & $\stackrel{\bullet}{\circ}$ & $=$ & $\stackrel{\infty}{\circ}$ \\
\hline
\end{tabular}


172 Recurrent Skull Base Chordomas Yoo et al.

Table 4 Summary of phone interviews

\begin{tabular}{|l|l|l|}
\hline Symptom & N & $\%$ \\
\hline Headaches & 1 & 12.5 \\
\hline Visual field deficits & 1 & 12.5 \\
\hline Blurry vision & 0 & 0 \\
\hline Hearing loss & 1 & 12.5 \\
\hline Tinnitus & 2 & 25 \\
\hline Anosmia & 1 & 12.5 \\
\hline Dysgeusia & 0 & 0 \\
\hline Dysphasia & 0 & 0 \\
\hline Dysphagia & 1 & 12.5 \\
\hline Ambulatory difficulty & 0 & 0 \\
\hline Seizures & 0 & 0 \\
\hline Episodes of loss of consciousness & 0 & 0 \\
\hline Memory loss & 1 & 12.5 \\
\hline Total available for phone interview & 8 & \\
\hline
\end{tabular}

Note: A total of 8 out of 12 living patients were available for phone interview. After giving informed consent, the patients answered questions regarding their current symptoms.

Table 5 Literature review of reported outcomes on locally recurrent skull base chordomas

\begin{tabular}{|c|c|c|c|c|c|c|}
\hline Reference & $N$ & $\begin{array}{l}\text { Initial } \\
\text { treatment } \\
\text { modality }\end{array}$ & $\begin{array}{l}\text { Salvage } \\
\text { treatment } \\
\text { modality }\end{array}$ & $\begin{array}{l}\text { Salvage treatment } \\
\text { details }\end{array}$ & $\begin{array}{l}\text { Outcomes specific to } \\
\text { recurrent population }\end{array}$ & Toxicity \\
\hline $\begin{array}{l}\text { Fagundes et al, } \\
\text { IJROBP (Harvard) }\end{array}$ & $\begin{array}{l}N=45 \\
\text { (Skull base) } \\
N=18 \\
\text { (Cervical spine) }\end{array}$ & $\begin{array}{l}\mathrm{S}+\mathrm{RT} \\
\text { (PBRT) }\end{array}$ & Mostly S & $\begin{array}{l}\text { STR }(N=44) \\
\text { GTR }(N=2) \\
\text { RT alone }(N=1) \\
\text { Chemotherapy alone } \\
(N=1) \\
\text { CRT }(N=1)\end{array}$ & $\begin{array}{l}\text { Median interval to } \\
\text { progression =7 mo } \\
\text { (range } 4-50 \text { ) } \\
\text { 2-y OS } 63 \% \\
5 \text {-y OS } 6 \%\end{array}$ & $\begin{array}{l}\text { Not reported for the } \\
\text { subset of recurrent } \\
\text { population }\end{array}$ \\
\hline $\begin{array}{l}\text { Tzortzidis et al, } \\
\text { Neurosurgery } \\
\text { (University of } \\
\text { Washington) }\end{array}$ & $N=27$ & $\mathrm{~S} \pm \mathrm{RT}$ & $S$ & $\begin{array}{l}\text { Aggressive } \\
\text { microsurgical resection }\end{array}$ & $\begin{array}{l}3-y \text { RFS } 41 \%, 5-y \text { RFS } \\
39 \%, 10-y \text { RFS } 26 \%\end{array}$ & $\begin{array}{l}\text { Not reported for the } \\
\text { subset of recurrent } \\
\text { population }\end{array}$ \\
\hline $\begin{array}{l}\text { Ito et al, Acta } \\
\text { Neurochir (Japan) }\end{array}$ & $N=11$ & $\begin{array}{l}S+R T \\
\text { (GKRS) }\end{array}$ & $\mathrm{S}$ or RT & $\begin{array}{l}S(N=5) \\
\text { GKRS }(N=21) \text { with } \\
\text { mean marginal dose } \\
17.8 \text { Gy } \\
\text { Novalis }(N=1)\end{array}$ & $\begin{array}{l}\text { All tumors well-con- } \\
\text { trolled during follow-up } \\
\text { mean of } 71.2 \text { mo, range } \\
25-148 \text { mo }\end{array}$ & None \\
\hline $\begin{array}{l}\text { Sen et al, } \\
\text { J Neurosurg } \\
\text { (Mount Sinai) }\end{array}$ & $N=23$ & $\mathrm{~S} \pm \mathrm{RT}$ & $S$ & $\begin{array}{l}\text { Midline anterior } \\
\text { approach }(N=5), \\
\text { lateral approach } \\
(N=13) \text {, } \\
\text { combined }(N=5)\end{array}$ & 5 -y recurrence rate $81 \%$ & $\begin{array}{l}\text { Not reported for the } \\
\text { subset of recurrent } \\
\text { population }\end{array}$ \\
\hline $\begin{array}{l}\text { Jiang et al, J Clin } \\
\text { Neurosci (Stanford) }\end{array}$ & $N=9$ & $\begin{array}{l}\mathrm{S}+\mathrm{RT} \\
\text { (PBRT } \\
\text { or IMRT) }\end{array}$ & RT & $\begin{array}{l}\text { CKRS }(N=9) \text { with mean } \\
\text { marginal dose } 32.5 \mathrm{~Gy}\end{array}$ & $\begin{array}{l}28.6 \% \text { had stable or } \\
\text { improved outcomes }\end{array}$ & None \\
\hline $\begin{array}{l}\text { Bugoci et al AJCO } \\
\text { (Kaiser, Los Angeles) }\end{array}$ & $N=5$ & $\begin{array}{l}S+R T \\
\text { (FSRT) }\end{array}$ & $\begin{array}{l}\text { S or } \\
\text { molecular } \\
\text { targeted } \\
\text { therapy }\end{array}$ & $\begin{array}{l}\text { SRS } 18 \text { Gy, surgery } 9 \text { mo } \\
\text { after }(N=1) \\
\text { Surgery }(N=1) \\
\text { Gleevec }(N=2) \\
\text { Dasatinib }(N=1)\end{array}$ & $\begin{array}{l}3 \text { alive with stable } \\
\text { disease, } 1 \text { alive with } \\
\text { disease progression } \\
\text { after RT, } 1 \text { died of } \\
\text { disease } \\
\text { Overall survival range } \\
\text { 32-90.3 mo after initial } \\
\text { RT }\end{array}$ & $\begin{array}{l}\text { Not reported for the } \\
\text { subset of recurrent } \\
\text { population }\end{array}$ \\
\hline $\begin{array}{l}\text { McDonald et al, } \\
\text { IJROBP, (Indiana } \\
\text { University) }\end{array}$ & $N=16$ & $\mathrm{~S}+\mathrm{RT}$ & RT & $\begin{array}{l}\text { Proton therapy with } \\
\text { mean dose } 75.6 \mathrm{~Gy} \text { RBE } \\
\text { (range } 71.2-79.2 \mathrm{~Gy} \text { ) }\end{array}$ & $2-y$ LC $85 \%, 2-y$ OS $80 \%$ & $\begin{array}{l}\text { G3 bitemporal lobe } \\
\text { radionecrosis }(N=1) \\
\text { G4 CSF leak }(N=1) \\
\text { G4 brainstem stroke } \\
(N=1)\end{array}$ \\
\hline
\end{tabular}


Table 5 (Continued)

\begin{tabular}{|c|c|c|c|c|c|c|}
\hline Reference & $N$ & $\begin{array}{l}\text { Initial } \\
\text { treatment } \\
\text { modality }\end{array}$ & $\begin{array}{l}\text { Salvage } \\
\text { treatment } \\
\text { modality }\end{array}$ & $\begin{array}{l}\text { Salvage treatment } \\
\text { details }\end{array}$ & $\begin{array}{l}\text { Outcomes specific to } \\
\text { recurrent population }\end{array}$ & Toxicity \\
\hline $\begin{array}{l}\text { Uhl et al (University } \\
\text { of Heidelberg, } \\
\text { Germany) }\end{array}$ & $\begin{array}{l}N=20 \\
\text { (chordoma) } \\
N=5 \\
\text { (chondrosarcoma) }\end{array}$ & $\mathrm{S}+\mathrm{RT}$ & RT & $\begin{array}{l}\text { Carbon ion therapy, } \\
\text { median dose } 51 \text { GyE } \\
\text { (range 45-60 GyE) }\end{array}$ & $\begin{array}{l}\text { 2-y LPFS } 79.3 \% \\
1 \text { relapse for chondro- } \\
\text { sarcoma, } 5 \text { relapses for } \\
\text { chordomas }\end{array}$ & $\begin{array}{l}\text { G1 temporal lobe } \\
\text { reaction }(N=5) \\
\text { G2 mucositis }(N=1) \\
\text { G2 hypacusis }(N=3) \\
\text { G3 osteoradionecrosis } \\
(N=1)\end{array}$ \\
\hline $\begin{array}{l}\text { Chibbaro et al, } \\
\text { Neurosurg } \\
\text { Rev (France) }\end{array}$ & $N=22$ & $\mathrm{~S} \pm \mathrm{RT}$ & $S$ & $\begin{array}{l}\text { Endoscopic endonasal } \\
\text { approach with GTR } \\
(N=7) \text { or STR }(15)\end{array}$ & $\begin{array}{l}4(11 \%) \text { had recurrence, } \\
4(11 \%) \text { had progression } \\
\text { with mean follow-up of } \\
32 \text { mo }\end{array}$ & $\begin{array}{l}\text { Death due to bleeding } \\
\text { aneurysm }(N=1) \\
\text { Moderate CSF leakage } \\
(N=4) \\
\text { Meningitis }(N=8)\end{array}$ \\
\hline $\begin{array}{l}\text { Choy et al, J of } \\
\text { Neurosurg (UCLA) }\end{array}$ & $N=26$ & $\mathrm{~N} / \mathrm{A}$ & $\mathrm{S} \pm \mathrm{RT}$ & $\begin{array}{l}\text { Adjuvant SRS or SRT } \\
\text { using 6-MV Novalis } \\
\text { LINAC }\end{array}$ & $\begin{array}{l}\text { 1-y PFS } 72.9 \% \text { with } \\
\text { adjuvant RT, } 74 \% \\
\text { without adjuvant RT } \\
\text { 5-y PFS 36.5\% with } \\
\text { adjuvant RT and } 23.5 \% \\
\text { without adjuvant RT }\end{array}$ & $\begin{array}{l}\text { Not reported for the } \\
\text { subset of recurrent } \\
\text { population }\end{array}$ \\
\hline $\begin{array}{l}\text { Vasudevan et al, } \\
\text { Front Surg (UCSF) }\end{array}$ & $N=5$ & $\begin{array}{l}S+R T \\
\text { (PBRT, } \\
\text { FSRT) }\end{array}$ & RT & $\begin{array}{l}\text { FSRT }(N=5) \text { with } \\
\text { median dose } 37.5 \text { Gy in } \\
5 \text { fractions } \\
\text { Surgery }(N=1)\end{array}$ & $\begin{array}{l}\text { All significant events } \\
\text { occurred within } 1 \mathrm{y} \\
\text { following FSRT }\end{array}$ & $\begin{array}{l}\text { Not reported for the } \\
\text { subset of recurrent } \\
\text { population }\end{array}$ \\
\hline
\end{tabular}

Abbreviations: CKRS, cyber knife radiosurgery; CRT, chemotherapy and radiation; CSF, cerebrospinal fluid; FSRT, fractionated stereotactic radiation therapy; GKRS, gamma knife radiosurgery; GTR, gross total resection; IMRT, intensity-modulated radiation therapy; LC, local control; LINAC, linear accelerator; LPFS, local progression-free survival; OS, overall survival; PBRT, proton beam radiotherapy; PFS, progression-free survival; RBE, relative biological effectiveness; RFS, recurrence free survival; RT, radiation; S, surgical resection; SRS, stereotactic radiosurgery; SRT, surgery followed by adjuvant radiation; STR, subtotal resection; USC, University of Southern California.

\section{Conflict of Interest}

E.L.C. reports other from Brainlab, outside the submitted work.

\section{References}

1 Harsh GR, Vaz-Guimaraes F. Chordomas and Chondrosarcomas of the Skull Base and Spine. 2nd ed. London: Academic Press is an imprint of Elsevier; 2018

2 Hayat MA. Tumors of the Central Nervous System, Volume 8 Astrocytoma, Medulloblastoma, Retinoblastoma, Chordoma, Craniopharyngioma, Oligodendroglioma, and Ependymoma. Dordrecht: Springer Netherlands; 2012

3 Pamir MN, Al-Mefty O, Borba Luis AB, eds. Chordomas: Technologies, Techniques, and Treatment Strategies. New York, NY: Thieme Medical Publishers, Inc; 2017

4 Amichetti M, Cianchetti M, Amelio D, Enrici RM, Minniti G. Proton therapy in chordoma of the base of the skull: a systematic review. Neurosurg Rev 2009;32(04):403-416

5 Fung V, Calugaru V, Bolle S, et al. Proton beam therapy for skull base chordomas in 106 patients: a dose adaptive radiation protocol. Radiother Oncol 2018;128(02):198-202

6 Combs SE, Kalbe A, Nikoghosyan A, et al. Carbon ion radiotherapy performed as re-irradiation using active beam delivery in patients with tumors of the brain, skull base and sacral region. Radiother Oncol 2011;98(01):63-67

7 Hug EB, Loredo LN, Slater JD, et al. Proton radiation therapy for chordomas and chondrosarcomas of the skull base. J Neurosurg 1999;91(03):432-439

8 Sahgal A, Chan MW, Atenafu EG, et al. Image-guided, intensitymodulated radiation therapy (IG-IMRT) for skull base chordoma and chondrosarcoma: preliminary outcomes. Neuro-oncol 2015; 17(06):889-894

9 Yamada Y, Gounder M, Laufer I. Multidisciplinary management of recurrent chordomas. Curr Treat Options Oncol 2013;14(03): 442-453
10 Stacchiotti S, Gronchi A, Fossati P, et al. Best practices for the management of local-regional recurrent chordoma: a position paper by the Chordoma Global Consensus Group. Ann Oncol 2017;28(06):1230-1242

11 Fagundes MA, Hug EB, Liebsch NJ, Daly W, Efird J, Munzenrider JE. Radiation therapy for chordomas of the base of skull and cervical spine: patterns of failure and outcome after relapse. Int J Radiat Oncol Biol Phys 1995;33(03):579-584

12 Tzortzidis F, Elahi F, Wright D, Natarajan SK, Sekhar LN. Patient outcome at long-term follow-up after aggressive microsurgical resection of cranial base chordomas. Neurosurgery 2006;59(02): 230-237, discussion 230-237

13 Ito E, Saito K, Okada T, Nagatani T, Nagasaka T. Long-term control of clival chordoma with initial aggressive surgical resection and gamma knife radiosurgery for recurrence. Acta Neurochir (Wien) 2010;152(01):57-67, discussion 67

14 Sen C, Triana AI, Berglind N, Godbold J, Shrivastava RK. Clival chordomas: clinical management, results, and complications in 71 patients. J Neurosurg 2010;113(05):1059-1071

15 Jiang B, Veeravagu A, Lee M, et al. Management of intracranial and extracranial chordomas with CyberKnife stereotactic radiosurgery. J Clin Neurosci 2012;19(08):1101-1106

16 Bugoci DM, Girvigian MR, Chen JCT, Miller MM, Rahimian J. Photon-based fractionated stereotactic radiotherapy for postoperative treatment of skull base chordomas. Am J Clin Oncol 2013; 36(04):404-410

17 McDonald MW, Linton OR, Shah MV. Proton therapy for reirradiation of progressive or recurrent chordoma. Int J Radiat Oncol Biol Phys 2013;87(05):1107-1114

18 Uhl M, Welzel T, Oelmann J, et al. Active raster scanning with carbon ions: reirradiation in patients with recurrent skull base chordomas and chondrosarcomas. Strahlenther Onkol 2014;190 (07):686-691

19 Chibbaro S, Cornelius JF, Froelich S, et al. Endoscopic endonasal approach in the management of skull base chordomas-clinical experience on a large series, technique, outcome, and pitfalls. Neurosurg Rev 2014;37(02):217-224, discussion 224-225 
20 Choy W, Terterov S, Ung N, et al. Adjuvant stereotactic radiosurgery and radiation therapy for the treatment of intracranial chordomas. J Neurol Surg B Skull Base 2016;77(01):38-46

21 Vasudevan HN, Raleigh DR, Johnson J, et al. Management of chordoma and chondrosarcoma with fractionated stereotactic radiotherapy. Front Surg 2017;4:35

22 Krengli M, Apicella G, Deantonio L, Paolini M, Masini L. Stereotactic radiation therapy for skull base recurrences: is a salvage approach still possible? Rep Pract Oncol Radiother 2015;20(06):430-439

23 Kotecha R, Damico N, Miller JA, et al. Three or more courses of stereotactic radiosurgery for patients with multiply recurrent brain metastases. Neurosurgery 2017;80(06):871-879

24 Verma J, McCutcheon IE, Waguespack SG, Mahajan A. Feasibility and outcome of re-irradiation in the treatment of multiply recurrent pituitary adenomas. Pituitary 2014;17(06):539-545

25 Brito da Silva H, Straus D, Barber JK, Rostomily RC, Ferreira M Jr, Sekhar LN. Cranial chordoma: a new preoperative grading system. Neurosurgery 2018;83(03):403-415

26 Kano H, Iqbal FO, Sheehan J, et al. Stereotactic radiosurgery for chordoma: a report from the North American Gamma Knife Consortium. Neurosurgery 2011;68(02):379-389

27 Boari N, Gagliardi F, Cavalli A, et al. Skull base chordomas: clinical outcome in a consecutive series of 45 patients with long-term follow-up and evaluation of clinical and biological prognostic factors. J Neurosurg 2016;125(02):450-460

28 Jones PS, Aghi MK, Muzikansky A, Shih HA, Barker FG II, Curry WT Jr. Outcomes and patterns of care in adult skull base chordomas from the Surveillance, Epidemiology, and End Results (SEER) database. J Clin Neurosci 2014;21(09):1490-1496

29 Colli BO, Al-Mefty O. Chordomas of the skull base: follow-up review and prognostic factors. Neurosurg Focus 2001;10(03):E1

30 Wang L, Tian K, Wang K, et al. Factors for tumor progression in patients with skull base chordoma. Cancer Med 2016;5(09): 2368-2377

31 Dassoulas K, Schlesinger D, Yen CP, Sheehan J. The role of Gamma Knife surgery in the treatment of skull base chordomas. J Neurooncol 2009;94(02):243-248

32 Iyer A, Kano H, Kondziolka D, et al. Stereotactic radiosurgery for intracranial chondrosarcoma. J Neurooncol 2012;108(03): 535-542

33 Yasuda M, Bresson D, Chibbaro S, et al. Chordomas of the skull base and cervical spine: clinical outcomes associated with a multimodal surgical resection combined with proton-beam radiation in 40 patients. Neurosurg Rev 2012;35(02):171-182, discussion 182-183

34 Hasegawa T, Ishii D, Kida Y, Yoshimoto M, Koike J, Iizuka H. Gamma Knife surgery for skull base chordomas and chondrosarcomas. J Neurosurg 2007;107(04):752-757

35 Igaki $\mathrm{H}$, Tokuuye $\mathrm{K}$, Okumura $\mathrm{T}$, et al. Clinical results of proton beam therapy for skull base chordoma. Int J Radiat Oncol Biol Phys 2004;60(04):1120-1126

36 Koetje JH, Van Dam GM, Dille J, Nieuwenhuijs VB. Online collection of patient reported outcome measures: an effective method for follow-up of benign surgery. Clin Res Trials 2018;4(01):1 